\title{
Hibridación entre la codorniz común (Coturnix coturnix) y la codorniz de granja: estado de un problema de conservación
}

\author{
M. Puigcerver ${ }^{1}$, I. Sanchez-Donoso ${ }^{2,3}$, C. Vilà , F. Sardà-Palomera ${ }^{4,5}$, P.A. Morales-Rodríguez ${ }^{6}$, J.R. Caballero de la Calle ${ }^{6}$, \\ J.D. Rodríguez-Teijeiro ${ }^{2}$
}

(1) Departamento de Didáctica de las Ciencias Experimentales y la Matemática, Facultad de Formación del Profesorado, Universidad de Barcelona. Paseo Valle Hebrón, 171, 08035 Barcelona, España.

(2) Departamento de Biología Animal, Facultad de Biología, Universidad de Barcelona. Avda. Diagonal, 645, 08028 Barcelona, España.

(3) Estación Biológica de Doñana EBD-CSIC. Avda. Américo Vespucio, s/n, 41092 Sevilla, España.

(4) Institut Català d'Ornitologia. C/ Girona, 168, Esc. B, Entresuelo 3a , 08037 Barcelona.

(5) Àrea de Biodiversitat, Centre Tecnològic Forestal de Catalunya. Ctra. vella Sant Llorenç de Morunys Km 2, 25280 Solsona.

(6) Departamento de Ciencia y Tecnología Agroforestal y Genética, Escuela de Ingenieros Agrónomos de Ciudad Real, Universidad de Castilla-La Mancha. Rda. Calatrava 5, 13071 Ciudad Real, España.

* Autor de correspondencia: M. Puigcerver [mpuigcerver@ub.edu]

> Recibido el 1 de febrero de 2013, aceptado el 11 de abril de 2013.

Puigcerver, M., Sánchez-Donoso, I., Vilà, C., Sardà-Palomera, F., Morales-Rodríguez, P.A., Caballero de la Calle, J.R., Rodríguez-Teijeiro, J.D. (2013). Hibridación entre la codorniz común (Coturnix coturnix) y la codorniz de granja: estado de un problema de conservación. Ecosistemas 22(2):48-53. Doi.: 10.7818/ECOS.2013.22-2.08

Hibridación entre la codorniz común (Coturnix coturnix) y la codorniz de granja: estado de un problema de conservación. La hibridación entre especies es un fenómeno ampliamente extendido que puede tener consecuencias en la conservación de la biodiversidad. En el presente artículo se hace una revisión del problema de conservación derivado de la suelta de codornices de granja en poblaciones silvestres de codorniz común (Coturnix coturnix).

Estas codornices de granja han resultado ser, en la mayoría de casos, híbridos de codorniz común y codorniz japonesa (Coturnix japonica). Si no existen mecanismos de aislamiento reproductor, estas sueltas favorecerían la introgresión de genes de codorniz japonesa en las poblaciones de codorniz común; ello conllevaría que se produjera un "enjambre de híbridos" y la sedentarización de las poblaciones de codorniz, lo que comportaría muy probablemente su disminución en Europa.

Esta amenaza es real, al haberse demostrado que no hay mecanismos de aislamiento reproductor, ni pre-cigóticos, ni post-cigóticos, ni ecológicos. Sin embargo, datos empíricos sugieren que a pesar de ello no se produce el temido "enjambre de híbridos", sugiriéndose probablemente una mortalidad diferencial entre las dos especies como una posible explicación.

Finalmente, se sugieren algunas medidas de gestión derivadas de la situación actual, entre las que destacaría un control genético que certifique el origen de los individuos criados en granja y la prohibición de efectuar sueltas de codornices japonesas o híbridos.

Palabras clave: aislamiento reproductor, enjambre de híbridos, medidas de gestión, sueltas cinegéticas

Puigcerver, M., Sánchez-Donoso, I., Vilà, C., Sardà-Palomera, F., Morales-Rodríguez, P.A., Caballero de la Calle, J.R., Rodríguez-Teijeiro, J.D. (2013). Hybridization between the common quail (Coturnix coturnix) and farm-reared quails: state of the art of a conservation problem. Ecosistemas 22(2):48-53. Doi.: 10.7818/ECOS.2013.22-2.08

Hybridization between the common quail (Coturnix coturnix) and farm-reared quails: state of the art of a conservation problem. Hybridization between species is a widespread phenomenon which may have consequences in the conservation of the biodiversity. In this article we review the conservation problem derived from restocking practices with farm-reared quails in wild common quail populations (Coturnix coturnix).

Farm quails have resulted to be hybrids of common quail and Japanese quail (Coturnix japonica). If there are not reproductive isolating mechanisms, restocking practices could favour the introgression of Japanese quail genes into common quail populations, thus resulting in a hybrid swarm and increased sedentariness of quail populations which would probably result in a population decrease in Europe.

This is a real threat. There are neither pre-zigotic, post-zigotic, nor ecological barriers. However, empirical data does not suggest that a hybrid swarm has formed. Different rates of mortality between the species are a possible explanation.

Lastly, we suggest some management actions given the current situation. Among them, we suggest genetic certification of the origin of farm-reared individuals and banning the restocking with Japanese quail or hybrids.

Key words: game restocking, hybrid swarm, management measures, reproductive isolation 


\section{Antecedentes del tema y estado de la cuestión}

La hibridación es un fenómeno ampliamente extendido que se ha valorado de dos maneras: a) como un proceso natural, frecuente y probablemente infraestimado (Endler 1998, Mallet 2005) que puede generar variabilidad genética y nuevas especies (Grant y Grant 1992, Rhymer y Simberloff 1996, Arnold 1997, Allendorf et al. 2001); b) como un proceso que frecuentemente reduce la eficacia biológica de los individuos (Mayr 1992, Allendorf et al. 2001, Mallet 2005), llevando a los híbridos hacia un callejón evolutivo sin salida.

Desde el punto de vista de la conservación de fauna, la hibridación es a menudo considerada una amenaza, ya que especies autóctonas pueden ser desplazadas por otras alóctonas mediante la introgresión de genes. Esto puede ocurrir a partir de introducciones antrópicas de especies alóctonas, sean accidentales (McDowell 2002, Kidd et al. 2009) o deliberadas (Fischer y Lindenmayer 2000), o mediante modificaciones del hábitat que permiten que dos especies inicialmente aisladas entren en contacto (Levin et al. 1996, Rhymer y Simberloff 1996).

Las reintroducciones antrópicas pueden deberse principalmente al interés por restaurar poblaciones amenazadas (Massemin-Challet et al. 2006, Armstrong y Seddon 2008, Santos et al. 2009), o para incrementar capturas piscícolas o cinegéticas (Fischer y Lindenmayer 2000, Blanco-Aguiar et al. 2008, Barbanera et al. 2010).

Dentro de las Galliformes, son muy frecuentes las reintroducciones de especies o poblaciones alóctonas para incrementar la caza (Derégnaucourt et al 2002, Barbanera et al. 2005, 2007, Puigcerver et al. 2007, Tejedor et al. 2007, Barbabanera et al. 2009, Blanco-Aguiar et al. 2008, Casas et al. 2012; ver también en este mismo monográfico Viñuela et al. 2013). Estas prácticas se llevan a cabo con individuos de dudoso origen genético criados en granjas, constituyendo una seria amenaza de contaminación genética para las poblaciones autóctonas.

Incluido en este grupo se encuentra la codorniz común (Coturnix coturnix). La distribución de esta especie abarca desde las Islas Británicas hasta el lago Baikal y desde el Círculo Polar Ártico hasta los Trópicos (Del Hoyo et al. 1994, Guyomarc'h et al. 1998, Johnsgard 1998). Presenta un estado de conservación desfavorable (SPEC 3) y sus poblaciones se hallan mermadas debido a un largo declive histórico (Burfield 2004). Pese a ello, es una especie cinegética muy popular en diversos países de Europa (España, Francia, Italia y Grecia). Actualmente se considera que es una aloespecie de la codorniz japonesa (Coturnix japonica), que se halla distribuida por la mayor parte de Rusia y el este de Asia, incluyendo Japón, Corea, China y la India (Johnsgard 1998). Aunque la mayor parte del área de distribución de las dos especies es disjunta, existe una pequeña área de simpatría (Fig. 1) alrededor del lago Baikal (Kozlova 1932, Izmailov 1967, Fefelov 1998). A pesar de este solapamiento no hay evidencia clara de hibridación natural en la zona (Moreau y Wayre 1968, Del Hoyo et al. 1994, Guyomarc'h et al. 1998), si bien Barilani et al. (2005) muestran algún posible indicio.

Sin embargo, aunque no haya una conspicua hibridación natural entre la codorniz común y la codorniz japonesa, ésta sí se puede dar en el campo debido a las sueltas cinegéticas de codornices criadas en granja en algunos países como España (Rodríguez-Teijeiro et al. 1993), Portugal y Francia hasta 2002 (Guyomarc'h 2003), Italia (Galli 2003) y Grecia (Tsiompanoudis et al. 2011).

Recientemente se ha desarrollado una nueva cepa en granjas de cría para efectuar sueltas con finalidades cinegéticas. A pesar de la opacidad que rodea habitualmente al proceso de cría en las granjas, se ha sugerido que se ha efectuado una selección a base de cruzar codorniz común con codorniz japonesa, obteniéndose, al cabo de varias generaciones, unos individuos híbridos que son morfológicamente indistinguibles de la codorniz común silvestre. La razón por la que no se cría codorniz común en granjas es que, al no estar adaptada a la cautividad, no es productiva en términos económicos, al contrario que la codorniz japonesa y los híbridos.
Cabría preguntarse por qué la suelta de individuos de codorniz japonesa o híbridos puede constituir una amenaza para la población de codorniz común. La respuesta es múltiple, pero en particular se ha señalado que la codorniz común es una especie migradora parcial (Guyomarc'h 2003), mientras que la codorniz japonesa doméstica ha perdido su impulso migratorio como consecuencia de la selección impuesta durante su proceso de domesticación (Derégnaucourt et al. 2005). De acuerdo con estos investigadores, dado que las codornices híbridas tienen una menor frecuencia de fenotipos migratorios (Derégnaucourt et al. 2004), sus cruces con codornices salvajes podría causar una disminución en las tendencias migratorias de la codorniz común y un descenso dramático en los individuos migradores que llegan a Europa.

Estos cruces podrían llevar a un rápido incremento en la proporción de híbridos en las poblaciones de codorniz común ya que, una vez que el proceso de hibridación ha empezado, es muy difícil de parar cuando los híbridos son fértiles y se aparean con otros híbridos y con individuos de los linajes parentales (Allendorf et al. 2001). Al cabo de unas pocas generaciones, este proceso daría lugar a lo que se conoce como un "enjambre de híbridos" ("hybrid swarm") en el que, esencialmente, todos los individuos son de origen híbrido (Huxel 1999, Allendorf et al. 2001), conduciendo a un colapso de la población autóctona.

Esta amenaza no es teórica. Ya se han detectado híbridos en poblaciones de codorniz común durante la época reproductora en diferentes países europeos. No debe sorprender que Guyomarc'h (2003) exigiera cambios legales a nivel de la Unión Europea para frenar la introgresión de genes de codorniz japonesa, proponiendo la prohibición de la cría y comercialización de codorniz japonesa e híbridos con finalidades cinegéticas. Más recientemente, el plan de manejo de la codorniz común de la Unión Europea enfatiza la necesidad de prohibir las sueltas de codorniz japonesa y/o híbridos en Europa y en el resto del área de distribución de la codorniz común (Perennou 2009).

Ante este panorama, cabe efectuar diversas preguntas para evaluar el problema de conservación que se plantea. La primera es si realmente las codornices criadas en granja son híbridas. Anteriormente se ha comentado que se producen unos híbridos morfológicamente indistinguibles de la codorniz común, y los propietarios de las granjas afirman que producen codornices comunes puras. Ello nos conduce a la necesidad de efectuar análisis genéticos para poder establecer con claridad su origen. La segunda pregunta es si existe algún tipo de barrera pre o post-cigótica que

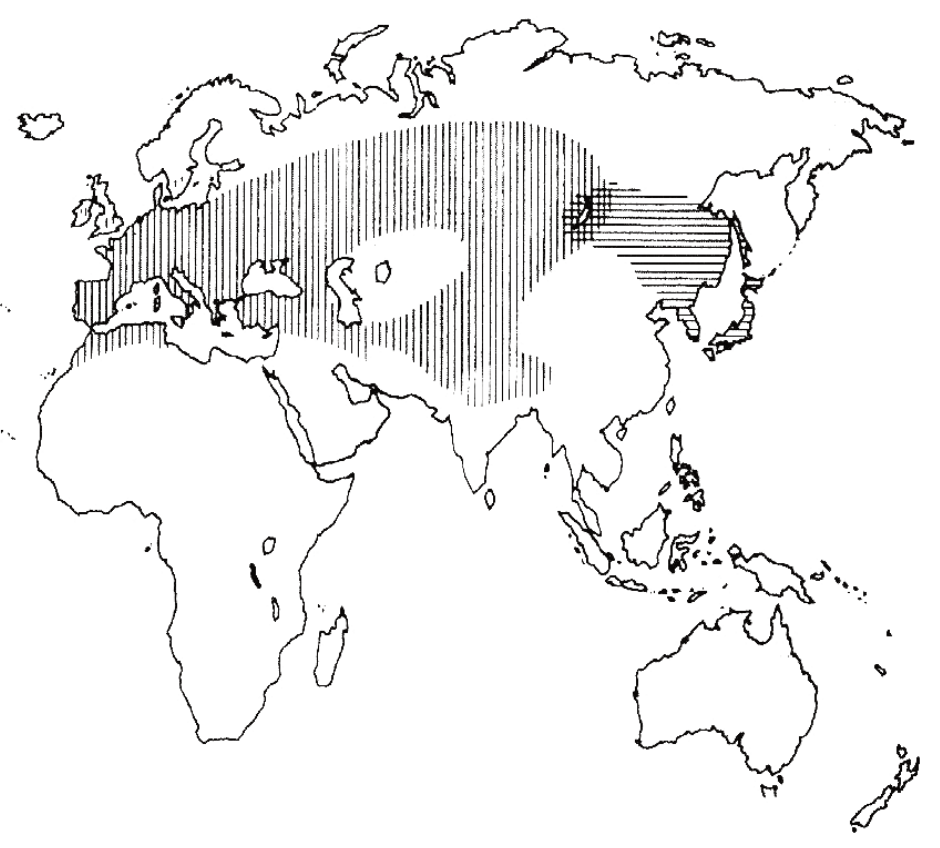

Figura 1. Áreas de cría de la codorniz común (líneas verticales) y la codorniz japonesa (líneas horizontales), mostrando el área de solapamiento entre las dos especies. 
impida el cruzamiento en el campo de la codorniz común con los individuos presuntamente híbridos que se utilizan para efectuar las sueltas con finalidades cinegéticas. La tercera, si existe algún tipo de barreras ecológicas que evitarían los cruzamientos en el campo entre codorniz común e híbridos. La cuarta, cuál sería la situación actual de las poblaciones de codorniz común y si se ha llegado ya al temido "enjambre de híbridos". Seguidamente, vamos a intentar dar respuesta a estas preguntas y a contestar: ¿cuál es el estado de la cuestión en la actualidad?

\section{¿Son híbridas las codornices criadas en granjas cinegéticas?}

Existen evidencias que inducen a pensar que sí o que, cuanto menos, que la hibridación en las granjas es un fenómeno ampliamente extendido. Se han encontrado evidencias comportamentales de hibridación en individuos de una granja francesa y de otra italiana (Derégnaucourt et al. 2005), en las que 10 machos de 27 (de la granja francesa) y 40 machos de 44 (de la granja italiana) no mostraron ninguna inquietud migradora característica de los machos de codorniz común. Por otra parte, 21 de 27 machos de la granja francesa emitieron cantos de apareamiento similares a los producidos por una línea control de codornices híbridas (codorniz japonesa $x$ codorniz común), mientras que en la granja italiana este canto híbrido se detectó en 5 de los 22 machos analizados.

Pasando a las evidencias directas, Amaral et al. (2007) efectuaron un análisis molecular con el gen del citocromo $b$ del ADN mitocondrial y con cinco microsatélites de ADN nuclear. Mostraron claramente que los 22 individuos analizados provenientes de una granja portuguesa, en la que el propietario aseguraba criar únicamente codorniz común, eran híbridos. Más recientemente, un estudio llevado a cabo con ADN nuclear (11 microsatélites autosómicos no ligados) sobre 52 individuos de cinco granjas cinegéticas españolas distintas mostró que, contrariamente a lo declarado por los propietarios de las granjas, entre el $85 \%$ y el $90 \%$ no eran codorniz común pura, mostrando signos evidentes de mezcla con codorniz japonesa. La mayor parte de los individuos eran codorniz japonesa o híbridos de segunda generación (Sanchez-Donoso et al. 2012). Entre un $4 \%$ y un $15 \%$ de los individuos analizados fueron identificados como codorniz común, lo que podría reflejar ocasionales introducciones de codornices comunes en las poblaciones de granja para actuar como reproductores, reduciendo la consanguinidad y la carga genética de codorniz japonesa doméstica.

\section{¿Existen barreras pre- o post-cigóticas entre la codorniz común y la codorniz japonesa?}

\section{Barreras pre-cigóticas}

Los requerimientos de hábitat de la codorniz común y la codorniz japonesa son prácticamente idénticos (Taka-Tsukasa 1941), por lo que el factor hábitat no debe constituir una barrera reproductora.

La codorniz común y la codorniz japonesa se diferencian en el canto de apareamiento de los machos. Mientras que el canto de los machos de codorniz japonesa tiene una estructura formada por dos notas cortas seguidas por una tercera nota larga, con los espacios entre notas de similar duración, el canto del macho de codorniz común tiene tres notas de la misma duración, con un lapso de tiempo largo entre las dos primeras notas y prácticamente sin lapso entre la segunda y la tercera nota. Los híbridos, en promedio, presentan un canto intermedio entre los cantos de las dos especies, si bien existe una gran variabilidad interindividual (Collins y Goldsmith 1998). Contrariamente, las hembras de codorniz común, de japonesa o híbridos, tienen un canto prácticamente idéntico.

Dado que durante el proceso de selección de pareja es la hembra de codorniz la que selecciona al macho (J.D.R. y M.P.O., obs. pers.), cabría preguntarse si ambas especies son capaces de discriminar a sus co-específicos. De no ser así el comportamiento podría constituir un mecanismo de aislamiento pre-cigótico.
Existen experimentos llevados a cabo en cautividad con 31 hembras de codorniz común que muestran cómo éstas emiten el máximo número de cantos de respuesta a la reproducción de cantos de machos cuando quienes los emiten son co-específicos. En cambio, el menor número de respuestas de hembras de codorniz común lo obtenían los cantos de machos de codorniz japonesa, mientras que los cantos de machos de codorniz híbridos provocaban una frecuencia de respuestas intermedia (Derégnaucourt y Guyomarc'h 2003). El mismo experimento realizado con 16 hembras de codorniz japonesa mostró que ésta no era selectiva y que respondía por un igual a los cantos de machos de codorniz común, de codorniz japonesa y de híbridos. Esto sugiere que la hembra de codorniz común presenta únicamente una discriminación parcial co-específica en lo relativo a la elección de pareja y podría eventualmente emparejarse con un macho híbrido en condiciones naturales. Por otra parte, dado que la hembra de codorniz japonesa no presenta ninguna discriminación co-específica, sus sueltas en áreas de reproducción de la codorniz común pueden comportar fácilmente la formación de parejas hetero-específicas.

Por otra parte, las hembras híbridas colocadas como cebo sexual en el interior de jaulas-nasa dispuestas en áreas de reproducción de la codorniz común no solamente atraen machos criados en granjas, sino que además consiguen atraer más machos de codorniz común que las propias hembras de codorniz común cuando éstas son utilizadas en experiencias similares. En este sentido, un experimento llevado a cabo con jaulas-nasa colocadas en el campo ha mostrado que las que contenían hembras de granja como cebo sexual atraían 2.58 veces más machos de codorniz común que las jaulas que contenían hembras de codorniz común (M.P.O., I.S.D., C.V.A., F.S.P., J.D.R.T., obs. pers.).

En definitiva, no se ha desarrollado ninguna discriminación basada en el canto por parte de los machos de codorniz común, que son atraídos tanto por hembras de codorniz común como por hembras japonesas o híbridas, mientras que en las hembras de codorniz común existe una discriminación parcial y que, por tanto, no lograría evitar enteramente la formación de parejas hetero-específicas. Por todo ello, probablemente se producen más apareamientos entre hembras híbridas con machos de codorniz común que entre hembras de codorniz común con machos híbridos.

\section{Barreras post-cigóticas}

Pese a algunos resultados de estudios antiguos indicando lo contrario (Lepori 1964, Pala y Lissia-Frau 1966, Moreau y Wayre 1968), recientemente se ha estableciendo que no hay mecanismos de aislamiento post-cigótico entre ambas especies en cautividad (Derégnaucourt et al. 2002). Este último estudio se llevó a cabo realizando cruces con un grupo de 20 individuos de codorniz japonesa y 26 individuos de codorniz común. Los resultados mostraron que tanto los híbridos de la primera y segunda generación como los retrocruzamientos son fáciles de obtener en condiciones de cautividad. La fertilidad de las parejas híbridas y el éxito de eclosión de centenares de huevos no se diferenciaron significativamente de los obtenidos de parejas de codorniz común criados bajo las mismas condiciones. Los mismos resultados se obtuvieron con tres grupos de cruzamiento involucrando a los híbridos de la primera generación. Por tanto, no se pudo detectar esterilidad ni menor viabilidad de los híbridos.

Estos resultados indican claramente que los apareamientos hetero-específicos son perfectamente viables en cautividad, por lo que las sueltas constituyen un riesgo real de introgresión genética en las poblaciones silvestres de codorniz común.

\section{¿Existen barreras ecológicas entre la codorniz común y la codorniz híbrida?}

Se ha detectado, mediante la aplicación de técnicas moleculares diversas, la presencia de individuos híbridos durante la época de cría en áreas de reproducción de la codorniz común en diferentes países europeos. 
Así, 11 individuos cazados en Portugal (de un total de 35) e inicialmente identificados como codorniz común tenían genotipos mezcla de ésta y de codorniz japonesa (Amaral et al. 2007).

En Francia, Chazara et al. (2006), a partir de una muestra de 90 individuos cazados y considerados codornices comunes, detectaron que en tres de ellos el ADN mitocondrial analizado era de codorniz japonesa, y sus genotipos de ADN nuclear los situaban en un lugar intermedio entre la codorniz común y la codorniz japonesa. Posteriormente, los análisis genéticos de una muestra de 375 codornices comunes de Francia, España y Marruecos demostraron que 8 de ellos no lo eran: dos fueron identificados como codorniz japonesa pura, uno probablemente fue el resultado de un retrocruzamiento con codorniz japonesa, tres fueron híbridos de primera/segunda generación y dos fueron el resultado de probables retrocruzamientos con codorniz común (Chazara et al. 2010).

En Italia y en España en su conjunto, cerca de un $9 \%$ de las codornices capturadas e inicialmente identificadas como codorniz común, resultaron ser híbridas (Barilani et al. 2005). En concreto, de 22 individuos capturados en migración en Italia y considerados "a priori" como codorniz común, dos resultaron ser híbridos, mientras que en España, de una muestra de 145 individuos capturados durante la época de cría, 13 eran híbridos.

Queda clara, por tanto, la presencia de individuos híbridos en las poblaciones silvestres de codorniz común de diferentes países europeos. Sin embargo, ello no implica necesariamente que esto sea el resultado de la reproducción entre las codornices de granja y codorniz común. Durante muchos años, las sueltas con fines cinegéticos de individuos criados en granja (y que ahora sabemos que son híbridos) han sido una práctica habitual en varios países mediterráneos, como Italia (Galli 2003), Grecia (Tsiompanoudis et al. 2011), Serbia, Montenegro, Rumania y España (Rodríguez-Teijeiro et al. 1993, Puigcerver et al. 2007). Aunque en la actualidad estas prácticas se han prohibido en algunos países (en Portugal y en Francia desde 2002 y en Grecia desde 2007), podrían seguir haciéndose de forma ilegal. En otros países, como en España, existen ciertos "agujeros" legales. Así, aunque la Ley de Patrimonio Natural y Biodiversidad (Ley 42/2007) prohíbe la suelta de codornices alóctonas (sin haber definido previamente el término), (España 2007), en el Catálogo Español de Especies Exóticas Invasoras se hace referencia únicamente a la codorniz japonesa (Coturnix japonica), sin mencionarse para nada los híbridos entre ésta y la codorniz común (España 2011). El resultado final es que en la actualidad se siguen soltando muchas codornices de granja híbridas asumiéndose, sin ningún tipo de control genético, que se trata de codornices puras. Para hacernos una idea de la magnitud del tema, según consta en los planes de ordenación cinegética de la Generalitat de Cataluña, solamente en esta comunidad autónoma se soltaron anualmente más de 68000 individuos de granja durante el período 1990-2006. Esta cifra es muy elevada si se tiene en consideración que la población estimada de codorniz común en Cataluña oscila entre 5347 y 20847 individuos (Rodríguez-Teijeiro et al. 2004). Otra cifra llamativa es que, en Francia, durante la temporada de caza de 1983, de un total de 640000 individuos cazados, entre 430000 y 480000 resultaron ser individuos que presentaban rotos los extremos de las primarias más externas; ello sugiere se trataba de individuos que habían vivido previamente en cautividad (Guyomarc'h 2003), y hace pensar que la intensidad de sueltas de codornices de granja en aquella época era muy alta.

En definitiva, dada la masiva suelta de animales de origen híbrido procedentes de granjas, podría ocurrir que los híbridos detectados en el campo fueran algunos de los individuos nacidos en granjas y liberados posteriormente con fines cinegéticos (como sugieren algunos resultados obtenidos en Puigcerver et al. 2007), sin que esto implique reproducción entre los animales de granja y los salvajes. De hecho, actualmente no existen en la bibliografía evidencias directas de apareamiento entre la codorniz común y los híbridos en condiciones naturales. Por otra parte, Pierotti y Annet (1993) señalan que es muy sencillo obtener híbridos en cautividad a partir de algunas especies, aunque en condiciones naturales no se puedan cruzar debido a la existencia de barreras ecológicas.
Sin embargo, resultados obtenidos por nuestro grupo con 51 hembras híbridas y 16 hembras de codorniz común radiomarcadas han demostrado que las codornices híbridas y las codornices comunes sí se cruzan en la naturaleza, así como que las hembras híbridas tienen una mayor capacidad de atraer machos de codorniz común que las propias hembras de codorniz común (M.P.O., I.S.D., C.V.A., F.S.P., J.D.R., obs. pers.), como se ha mencionado más arriba. También se ha podido apreciar que las hembras híbridas que sobreviven el tiempo suficiente tienen el mismo éxito de apareamiento que las comunes, y las que se aparean tienen el mismo éxito de nidificación, siendo las tasas de fertilidad, eclosión y supervivencia de los pollos muy similares entre ambas especies. Por tanto, no existen barreras ecológicas que aíslen reproductivamente los híbridos de la codorniz común en condiciones naturales. Ahora bien, aunque las hembras híbridas tengan la misma probabilidad de aparearse y de hacer nidos que las hembras comunes, esta probabilidad depende del número de días en que las hembras permanecen en el área de estudio, que a su vez, depende básicamente de la tasa de mortalidad.

\section{¿Cuál es la situación actual de las poblaciones silvestres de codorniz común? ¿Se ha llegado ya al "enjambre de híbridos"?}

Nuestro grupo dispone de una serie larga de datos (Puigcerver et al. 2007,2012 ) a partir de un seguimiento poblacional en tres localidades catalanas entre 1983 y 2011. El primer híbrido se detectó en 1990 (Rodríguez-Teijeiro et al. 1993), coincidiendo con el inicio de las sueltas de codornices criadas en granja. En los subsiguientes 21 años, el número de híbridos censados (en base a su estructura del canto) fue del $2.2 \%$ del total de individuos capturados. Como el método empleado infraestima la proporción de híbridos en un 50 \% (Puigcerver et al. 2007) debido a que híbridos de varias generaciones son indistinguibles por el canto de la codorniz común, una estima más realista serían $4.4 \pm 0.66 \%$ híbridos al año.

Durante este período (1990-2010), no se observó ninguna tendencia al aumento en el número de híbridos con el paso del tiempo (coeficiente de regresión $=0.18 \pm 0.17 ; R^{2}=0.001 ; F_{1,20}=0.028$, $\mathrm{p}>0.05$, Fig. 2). Por tanto, a pesar del elevadísimo número de híbridos soltados durante dicho período en Cataluña, no se ha producido un "enjambre de híbridos", ni siquiera una tendencia al aumento.

Una posible explicación a esta discrepancia entre lo esperado y lo observado sería que los híbridos que se sueltan tuvieran una elevada tasa de mortalidad, como sugiere Guyomarc'h (2003). Resultados preliminares obtenidos por nuestro grupo referentes a la viabilidad de las parejas mixtas en el campo sugieren que las hembras de granja tienen una mayor mortalidad y, consecuentemente, una menor productividad que las hembras de codornices comunes puras; análogamente, Casas et al. (2012) demuestran que las

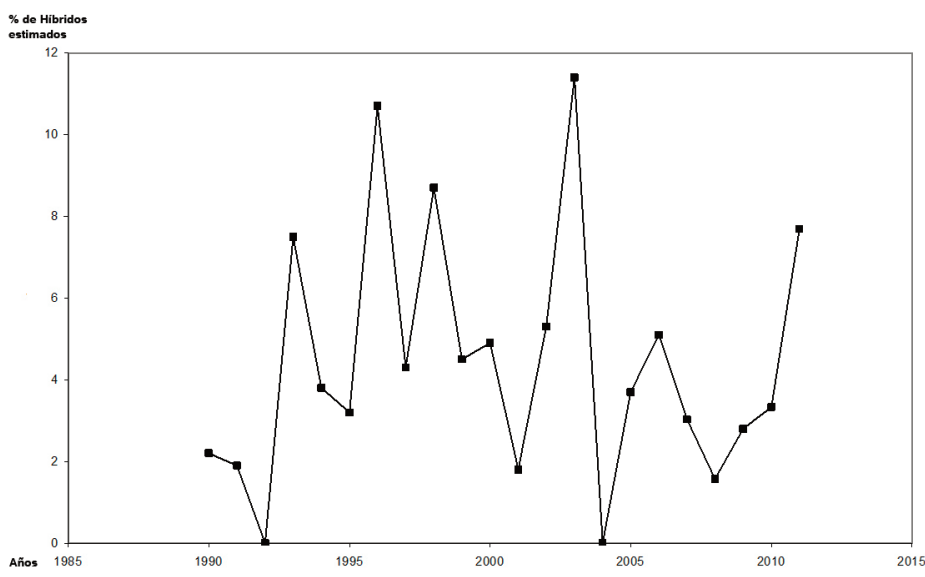

Figura 2. Estimas del porcentaje de híbridos detectados en tres áreas de estudio de Cataluña durante el período 1990-2011. 
perdices rojas de granja tienen una tasa de supervivencia en el campo significativamente menor que la de las perdices rojas silvestres.

\section{Estado de la cuestión en la actualidad}

Los resultados expuestos podrían sugerir que la suelta de híbridos no genera un serio problema de conservación.

No obstante, debe tenerse presente que, muy a menudo, el que una especie no nativa se convierta en invasora implica una fase de demora que puede durar décadas, seguida de una fase de rápido incremento exponencial tanto en número como en distribución (Mack et al. 2000).

Por otra parte, se podría estar dando un proceso de introgresión genética no detectable a partir la estructura del canto de los individuos; en este sentido, un análisis genético de la evolución temporal del porcentaje de individuos híbridos hallados en el campo podría aclarar si se está produciendo la introgresión de genes de la codorniz japonesa. Ante todo lo expuesto anteriormente, consideramos que este tipo de estudios debería ser una prioridad a corto-medio plazo.

Finalmente no hay que olvidar que, al margen de la contaminación genética, la introducción de individuos de granja puede comportar otro tipo de amenazas, como la transmisión de agentes patógenos que podrían causar una sustancial mortalidad en las poblaciones silvestres (Peeler et al. 2006).

Por todo ello, y aplicando el principio de precaución, sería absolutamente recomendable tomar todas las medidas necesarias para evitar las sueltas en el campo de codorniz japonesa o híbridos, así como regular más eficazmente unas hipotéticas sueltas de codorniz común pura.

En España, la vigente Ley 42/2007 del Patrimonio Natural y de la Biodiversidad prohíbe, en relación con la actividad cinegética, la introducción de especies alóctonas; asimismo, señala que la inclusión en el Catálogo Español de Especies Exóticas invasoras de una determinada especie conlleva la prohibición genérica de su posesión, transporte, tráfico y comercio, tanto de ejemplares vivos como muertos (España 2007). Sin embargo, el Catálogo únicamente ha incluido la codorniz japonesa (Coturnix japonica) (España 2011), sin mencionar en el mismo los híbridos entre codorniz común y codorniz japonesa, que son los que mayoritariamente se utilizan para efectuar las sueltas cinegéticas. Por otra parte, no queda claro en la redacción de la Ley 42/2007 si una codorniz híbrida es una especie alóctona o no; en el caso de que se interpretara que sí lo es, quedaría por resolver el tema de qué hacer cuando el propietario de una granja declara que cría codorniz común pura. Ello conllevaría, en aras de un estricto cumplimiento del espíritu de la ley, la necesidad de implementar inspecciones efectivas acerca de los procedimientos llevados a cabo en las granjas cinegéticas, lo que incluiría la obligatoriedad de efectuar análisis genéticos para certificar el origen de los individuos que se suelten.

\section{Agradecimientos}

A la "Direcció General de la Recerca" (2009-SGR-481), el antiguo Ministerio de Ciencia e Innovación (proyectos CGL200405308/BOS y CGL2007-63199), a la Federación de Caza de Euskadi (2007 a 2009), al "Departament de Medi ambient" de la Generalitat de Catalunya y a la "Agència de Gestió d'Ajuts Universitaris i de Recerca" de la Generalitat de Catalunya por su soporte económico. Ana Domínguez, Cristina Extremera e Irene Jiménez asistieron a los autores en el trabajo de campo.

\section{Referencias}

Allendorf, F.W., Leary, R.F., Spruell, P., Wenburg, J.K. 2001. The problems with hybrids: setting conservation guidelines. Trends in Ecology and Evolution 16(11):613-622. doi:10.1016/S0169-5347(01)02290-X
Amaral, A.J., Silva, A.B., Grosso, A. R., Chikhi, L., Bastos, C. 2007. Detection of hybridization and species identification in domesticated and wild quails using genetic markers. Folia Zoologica 56(3):285-300.

Armstrong, D.P., Seddon, P.J. 2008. Directions in reintroduction biology. Trends in ecology and evolution 23(1):20-5. doi:10.1016/j.tree.2007.10.003

Arnold, M.L. 1997. Natural hybridization and Evolution. Oxford University Press, Oxford, Reino Unido.

Barbanera, F., Negro, J.J., Di Giuseppe, G., Bertoncini, F., Cappelli, F., Dini, F. 2005. Analysis of the genetic structure of red-legged partridge (Alectoris rufa, Galliformes) populations by means of mitochondrial DNA and RAPD markers: a study from central Italy. Biological Conservation 122(2):275-287. doi:10.1016/j.biocon.2004.07.017

Barbanera, F., Guerrini, M., Hadjigerou, P., Panayides, P., Sokos, C., Wilkinson, P., Khan, A., Capelli, F., Dini, F. 2007. Genetic insight into Mediterranean chukar (Alectoris chukar, Galliformes) populations inferred from mitochondrial DNA and RAPD markers. Genetica 131(3):287-98. doi:10.1007/s10709-006-9138-X

Barbanera, F., Guerrini, M., Khan, A., Panayides, P., Hadjigerou, P., Sokos, C., Gombobaatar, S., Khan, P., Tofanelli, S. et al. 2009. Human-mediated introgression of exotic chukar (Alectoris chukar, Galliformes) genes from East Asia into native Mediterranean partridges. Biological Invasions 11(2):333-348. doi:10.1007/s10530-008-9251-0

Barbanera, F., Pergams, O.R.W., Guerrini, M., Forcina, G., Panayides, P., Dini, F. 2010. Genetic consequences of intensive management in game birds. Biological Conservation 143(5):1259-1268. doi:10.1016/j.biocon.2010.02.035

Barilani, M., Deregnaucourt, S., Gallego, S., Galli, L., Mucci, N., Piombo, R., Puigcerver, M., Rimondi, S., Rodríguez-Teijeiro, J.D. et al. 2005. Detecting hybridization in wild (Coturnix c. coturnix) and domesticated (Coturnix c. japonica) quail populations. Biological Conservation 126(4):445-455. doi:10.1016/j.biocon.2005.06.027

Blanco-Aguiar, J. A., González-Jara, P., Ferrero, M.E., Sánchez-Barbudo, I., Virgós, E., Villafuerte, R., Dávila, J. A. 2008. Assessment of game restocking contributions to anthropogenic hybridization: the case of the Iberian red-legged partridge. Animal Conservation 11(6):535-545. doi:10.1111/j.1469-1795.2008.00212.x

Burfield, I. (2004). Birds in Europe. Population estimates,trends and conservation status. Birdlife International, Cambridge Reino Unido.

Casas, F., Mougeot, F., Sánchez-Barbudo, I., Dávila, J. A., Viñuela, J. 2012. Fitness consequences of anthropogenic hybridization in wild red-legged partridge (Alectoris rufa, Phasianidae) populations. Biological Invasions 14(2):295-305. doi:10.1007/s10530-011-0062-3

Chazara, O., Lumineau, S., Minvielle, F., Roux, D., Feve, K., Kayang, B., Boutin, J.-M., et al. 2006. Étude des risques d 'introgression génétique de la caille des blés (Coturnix coturnix japonica): comparaison et intégration des données comportementales et moléculaires obtenues dans le sud-est de la France. Les Actes du BRG 6:317-334.

Chazara, O., Minvielle, F., Roux, D., Bed'hom, B., Feve, K., Coville, J.L., Kayang, B.B., Lumineau, S., Vignal, A., Boutin, J.-M., Rognon, X. 2010. Evidence for introgressive hybridization of wild common quail (Coturnix coturnix) by domesticated Japanese quail (Coturnix japonica) in France. Conservation Genetics 11:1051-1062.

Collins, S.A., Goldsmith, A.R. 1998. Individual and species differences in quail calls (Coturnix c. japonica, Coturnix c. coturnix and a hybrid). Ethology 104:977-990.

Del Hoyo, J., Elliot, A., Sargatal, J. 1994. Handbook of the Birds of the World. New World Vultures to Guineafowl. Lynx Edicions, Barcelona, España.

Derégnaucourt, S., Guyomarc'h, J.C. 2003. Mating Call Discrimination in Female European (Coturnix c . coturnix ) and Japanese Quail (Coturnix c. japonica). Ethology 109:107-119.

Derégnaucourt, S., Guyomarc'h, J.C., Aebischer, N. J. 2002. Hybridization between European Quail Coturnix coturnix and Japanese Quail Coturnix japonica. Ardea 90:15-21.

Derégnaucourt, S., Mitra, P.P., Fehér, O., Maul, K.K., Lints, T.J., Tchernichovski, O. 2004. Song development: in search of the error-signal. Annals of the New York Academy of Sciences 1016:364-376. doi:10.1196/annals.1298.036

Derégnaucourt, S., Guyomarc'h, J.-C., Spanò, S. 2005. Behavioural evidence of hybridization (JapanesexEuropean) in domestic quail released as game birds. Applied Animal Behaviour Science 94(3-4):303-318. doi:10.1016/j.applanim.2005.03.002

Endler, J.A. 1998. The place of hybridization in evolution. Evolution 52:640-644. 
España 2007. Ley 42/2007, de 13 de diciembre, del Patrimonio Natural y de la Biodiversidad. BOE 299, de 14 de diciembre de 2007, pp. 5127551327

España 2011. Real Decreto 1628/2011, de 14 de noviembre, por el que se regula el listado y catálogo español de especies exóticas invasoras. BOE 298, Lunes 12 de diciembre de 2011, pp. 132711-132735 http://www.boe.es/boe/dias/2011/12/12/pdfs/BOE-A-2011-19398.pdf

Fefelov, I.V. 1998. The Japanese quail in the Baïkal region. Ornithologischeskiy Zhurnal 50:24-26.

Fischer, J., Lindenmayer, D. 2000. An assessment of the published results of animal relocations. Biological Conservation 96(1):1-11. doi:10.1016/S0006-3207(00)00048-3

Galli, L. 2003. Caratterizzazione genetica di Quaglia Coturnix coturnix e rischi d'inquinamento genetico a seguito dell inmissioni di soggetti d'allevamento. Tesis doctoral, Università di Genova, Italia.

Grant, P.R., Grant, B.R. 1992. Hybridization of bird Species. Science 256:193-197.

Guyomarc'h, J. C. 2003. Elements for a common Quail (Coturnix c. coturnix) management plan. Game and Wildlife Science 20:1-92.

Guyomarc'h, J.C., Combreau, O., Puigcerver, M., Fontoura, P., Aebischer, N., Wallace, D.I. M. 1998. Coturnix coturnix Quail. Birds of Western palearctic Update 2:27-46.

Huxel, G.R. 1999. Rapid displacement of native species by invasive species: effects of hybridization. Biological Conservation 89:143-152.

Izmailov, I.V. 1967. Pittsy Vitimskogo ploskogor'ya (Birds of the Vitim Plateau). Buryat Pub. House, Ulan-Ude, Rusia.

Johnsgard, P.A. 1998. The Quail, Partridges and Francolins of the World. Oxford University Press, Oxford, Reino Unido.

Kidd, A.G., Bowman, J., Lesbarrères, D., Schulte-Hostedde, A. I. 2009. Hybridization between escaped domestic and wild American mink (Neovison vison). Molecular Ecology 18(6):1175-1186. doi:10.1111/j.1365-294X.2009.04100.x

Kozlova, E.V. 1932. The birds of south-west Transbaïkalia, northern Mongolia and central Gobi, Part II. Ibis, 13:431-437.

Lepori, N.G. 1964. Primi dati sugli ibridi di Coturnix c. japonica x Coturnix c. coturnix ottenuti in allevamento. Rivista Italiana di Ornithologia 34:192198.

Levin, D.A., Francisco-Ortega, J., Jansen, R.K. 1996. Hybridization and the Extinction of Rare Plant Species. Conservation Biology 10(1):10-16. doi:10.1046/j.1523-1739.1996.10010010.x

Mack, R.N., Simberloff, D., Lonsdale, W.M., Evans, H., Clout, M., Bazzaz, F. A. 200). Biotic invasions: causes, epidemiology, global consequences and control. Ecological applications 10:689-710.

Mallet, J. 2005. Hybridization as an invasion of the genome. Trends in Ecology and Evolution 20(5):229-237. doi:10.1016/j.tree.2005.02.010

Massemin-Challet, S., Gendner, J.-P., Samtmann, S., Pichegru, L., Wulgué, A., Le Maho, Y. 2006. The effect of migration strategy and food availability on White Stork Ciconia ciconia breeding success. Ibis 148(3):503508. doi:10.1111/j.1474-919X.2006.00550.x

Mayr, E. 1992. A local flora and the biological species concept. American Journal of Botany 79(2):222-238.
McDowell, N. 2002. Stream of escaped farm fish raises fears for wild salmon. Nature 416:571.

Moreau, R., Wayre, P. 1968. No On the Palearctic Quails. Ardea 56:209226.

Pala, M., Lissia-Frau, A.M. 1966. Ricerche sulla sterilita degli ibridi tra la Quaglia giaponesa (Coturnix c. japonica) e la quaglia europea (Coturnix c. coturnix). Rivista Italiana di Ornithologia 36:4-9.

Peeler, E., Thrush, M., Paisley, L., Rodgers, C. 2006. An assessment of the risk of spreading the fish parasite Gyrodactylus salaris to uninfected territories in the European Union with the movement of live Atlantic salmon (Salmo salar) from coastal waters. Aquaculture 258:187-197.

Perennou, C. 2009. European Union Management Plan 2009-2011. Common quail, Coturnix coturnix. European Communities, Luxemburgo.

Pierotti, R., Annet, C.A. 1993. Hybridization and male parental investment in birds. Condor 95:670-679.

Puigcerver, M., Vinyoles, D., Rodríguez-Teijeiro, J.D. 2007. Does restocking with Japanese quail or hybrids affect native populations of common quail Coturnix coturnix? Biological Conservation 136(4):628-635. doi:10.1016/j.biocon.2007.01.007

Puigcerver, M, Sardà-Palomera, F., Rodríguez-Teijeiro, J.D. 2012. Determining population trends and conservation status of the common quail (Coturnix coturnix) in Western Europe. Animal Biodiversity and Conservation 35(2):343-352.

Rhymer, J.M., Simberloff, D. 1996. Extinction by hybridisation and introgression. Annual Review of Ecology and Systematics 27:29-44.

Rodríguez-Teijeiro, J.D., Rodrigo-Rueda, F.J., Puigcerver, M., Gallego, S., Nadal, J. 1993. Codornices japonesas en nuestros campos. Trofeo 277:48-52.

Rodríguez-Teijeiro, J.D., Puigcerver, M., Gallego, S. 2004. Guatlla Coturnix coturnix. En: Estrada, J., Pedrocchi, V., Brotons, L., Herrando, S. (eds.), Atlas dels ocells nidificants de Catalunya 1999-2002, pp. 112113. ICO/Lynx Edicions, Barcelona, España.

Sanchez-Donoso, I., Vilà, C., Puigcerver, M., Butkauskas, D., Caballero de la Calle, J. R., Morales-Rodríguez, P.A., Rodríguez-Teijeiro, J. D. 2012. Are farm-reared quails for game restocking really common quails (Coturnix coturnix)?: a genetic approach. PloS one, 7(6):1-8. doi:10.1371/journal.pone.0039031

Santos, T., Pérez-Tris, J., Carbonell, R., Tellería, J.L., Díaz, J.A. 2009. Monitoring the performance of wild-born and introduced lizards in a fragmented landscape: Implications for ex situ conservation programmes. Biological Conservation 142(12):2923-2930. doi:10.1016/j.biocon.2009.07.017

Taka-Tsukasa, P. 1941. Birds of Nippon. Witherby, London, Reino Unido.

Tejedor, M.T., Monteagudo, L.V, Mautner, S., Hadjisterkotis, E., Arruga, M.V. 2007. Introgression of Alectoris chukar genes into a Spanish wild Alectoris rufa population. The Journal of Heredity 98(2):179-182. doi:10.1093/jhered/esm001

Tsiompanoudis, A., Kontsiotis, V., Bakaloudis, D. 2011. Observations of breeding and wintering European quail Coturnix coturnix in northern Greece. International Journal of Galliformes Conservation 2:36-37.

Viñuela, J., Casas, F., Díaz-Fernández, S., Delibes-Mateos, M., Mougeot, F., Arroyo, B. La perdiz roja (Alectoris rufa) en España: especie cinegética y amenazada. Ecosistemas 22(2):6-12. 